\title{
NATIVE SPEAKER PERCEPTIONS OF ACCENTED SPEECH: THE ENGLISH PRONUNCIATION OF MACEDONIAN EFL LEARNERS
}

\author{
ANASTAZIJA KIRKOVA-NASKOVA \\ akirkova@t-home.mk \\ Ss. Cyril and Methodius University
}

\begin{abstract}
The paper reports on the results of a study that aimed to describe the vocalic and consonantal features of the English pronunciation of Macedonian EFL learners as perceived by native speakers of English and to find out whether native speakers who speak different standard variants of English perceive the same segments as non-native. A specially designed computer web application was employed to gather two types of data: a) quantitative (frequency of segment variables and global foreign accent ratings on a 5point scale), and b) qualitative (open-ended questions). The result analysis points out to three most frequent markers of foreign accent in the English speech of Macedonian EFL learners: final obstruent devoicing, vowel shortening and substitution of English dental fricatives with Macedonian dental plosives. It also reflects additional phonetic aspects poorly explained in the available reference literature such as allophonic distributional differences between the two languages and intonational mismatch.
\end{abstract}

Key words: foreign accent, speech perception, native speaker, Macedonian English

\section{Introduction}

Research and teaching practice confirm that the characteristics of learners' L1 sound systems have a primary influence on speech production in L2. This is one reason why L2 pronunciation - or the development of phonological competence in L2 - demonstrates such great variability among second-language learners from different language backgrounds. For in attempting to master new or similar sounds, learners inevitably adapt their pronunciation under the influence of their native language. The resulting overlap between L1 and L2 is the phenomenon known as foreign-accented speech. This is strikingly evident in spoken interaction where phonological similarities and differences between a speaker's L1 and L2 provide quite reliable clues as to the listener's L1. However, a straightforward comparison between the sound systems of a speaker's L1 and L2 cannot reveal the subtle nuances that may facilitate or impede L2 sound acquisition and affect learner's L2 production. Furthermore, not all obvious differences in phonological phenomena are perceived by native-speakers as erroneous: some differences are tolerated and regarded as non-problematic while others are treated as deviant and conducive to unintelligibility and miscommunication. 
This paper presents the results of a web-based experiment where we aimed to describe the segmental features of the English pronunciation of Macedonian learners of English. We attempt at showing that their prior L1 phonological knowledge affects the acquisition of the L2 sound categories resulting in Macedonian-accented English speech. Based on the comparison between the sound systems of these languages, a number of pronunciation errors were predicted, which were then evaluated by native speakers of English as more or less problematic. Our goal was also to examine whether native speakers who speak different standard variants of English perceive the same segments as non-native.

\section{Acquiring L2 phonology: foreign accent and L1 influence}

In theory, L2 learners are expected to grasp the segmental and prosodic phonology of the target language. There is a great certainty that they will need to learn to perceive and produce new sounds, new phonotactic clusters, different types of syllable structure and an array of intonation patterns to convey a rich palette of meaning (Archibald 1998). The acquirement of these skills is not as effortless as might be assumed - it is a process that takes place gradually and draws on previously acquired L1 categories. Pennington (2007: 15) refers to the way in which this new sound system is developed as "piggybacking" on the L1 sound system.

In practice, no matter how successful L2 learners are in acquiring L2 phonology, it is highly likely that traces of foreign accent will remain in their pronunciation. Earlier attempts to define the notion of foreign accent focused on the concept of non-native speaker and the features of their L2 pronunciation, especially the influence of the native language. For instance, Piper and Cansin (1988: 334) underline the conventional understanding of foreign accent as denoting: "The flawed pronunciation of a non-native speaker of a language [that] has traditionally been attributed to transfer of elements of a learner's first language phonology to the second language phonology." In the past decade, however, researchers have acknowledged the greater complexity of this phenomenon by addressing other dimensions such as native-speaker perception, nativespeaker norms, and perceived identity. Accordingly, foreign-accented speech should be evaluated not only in its linguistic but also in its social context. Munro and Derwing (1995: 289) attempt to avoid negative stereotyping and define foreign accent as: "Nonpathological speech that differs in some noticeable respects from native speaker pronunciation norms."

Foreign-accentedness is widely understood to result from the complex interplay of various factors, including factors related to the particular characteristics of learners' native and non-native sound systems, learners' differing language experience, learners' individual aptitudes and needs, as well as the social environment in which language learning takes place (for more on these matters, see Piske, MacKay and Flege 2001; Leather and James 1996; Purcell and Sutter 1980; Hansen 2006). Of all these factors, it is the influence of L1 - also termed as transfer or interference-which has probably been subject to most extensive investigation, both theoretically and empirically. The influence of L1 is especially evident in segmental phonology, where pronunciation errors (phonemic, phonetic, allophonic and distributional) are explained as transfer errors due 
to the overlapping of the phonemic inventories of L1 and L2, though such influence is also noticeable at suprasegmental level where the stress, syllable structure, intonation and rhythm of L1 and L2 interact (Odlin 2000). In the 1960s, research based on contrastive analysis of the phonological systems of L1 and L2 aimed to explain the type of articulatory errors made by learners and the level of difficulty they experienced with L2 sounds (see Leather and James 1996; Major 1998). Recent theoretical models continue to base their postulates on the influence of L1 on L2, while emphasizing the effects of speech perception rather than focussing solely on production. In general, all models agree that learners tend to map L2 sounds onto L1 sound categories and predict possible learning scenarios depending on the similarity or dissimilarity of native and non-native sounds (see Best 1995; Kuhl 2000; Flege 1995, 2003; Brown 1998; Major 2001; Escudero 2005).

Whatever approach is taken, it may be assumed that similarities between L1 and L2 sounds or the non-existence of L2 sounds in the L1 sound inventory will prompt learners to make adaptations, i.e. to substitute the new/difficult sound with the closest acoustic and articulatory L1 sound and that this will inevitably be reflected in speech production as foreign-accented speech.

\section{Perception of foreign accent by native speakers}

Another issue which has occupied researchers over the years concerns the way in which native speakers perceive non-native speech. Native speakers are capable of accurately detecting traces of foreign accent in very short speech samples, single syllables, single vowels or consonants, and even in a $30 \mathrm{~ms}$ edited recording of a consonant in initial word position (Flege 1984). Although experienced listeners detect foreign-accentedness more reliably (Flege 1984; Thomson 1991), many studies have found that untrained listeners are also able to make appropriate evaluations of non-native speech (Brennan and Brennan 1981; Anderson-Hsieh and Koehler 1988; Derwing, Munro and Wiebe 1998).

If it is commonly accepted that native speakers posses the ability to promptly discern non-nativeness in the speech of L2 learners, the question arises as to which particular cues in the acoustic signal help them detect such foreign-accentedness. Scovel (1995) maintains that native speakers rely on non-linguistic acoustic information (such as speaker's voice quality settings and speaking rate) as well as their internal phonological knowledge about the phonemic structure of their native vowels, consonants and prosodic elements. Generally speaking, vowels are more indicative markers of foreign accent than consonants because they are "longer and usually of higher amplitude, frequently marked by syllabic stress, voiced and syllabic, carry the fundamental frequency of the voice and thus contain a great deal of prosodic information" (Scovel 1995: 175). However, not all vowels equally indicate traces of foreign accent; some phonemic contrasts, such as /i:/-/I/ in English, are not represented in most of the world's languages, hence they are more difficult for L2 learners to acquire and thus serve as indicators of foreign-accented speech to native speakers. Consonants demonstrate a similar pattern in that consonants with vowel characteristics, e.g. / / / and /1/, being sonorant sounds, are more informative in identifying foreign accents. Prosodic elements are thought to be by far the most prevalent indicators of foreign accent, especially when related to lexical and phrasal 
stress and syllable structure (Magen 1998), when speaker's L1 is a tonal language and/or when L1 and L2 demonstrate different rhythmical patterns, e.g. stress-timed vs. syllabletimed languages (van Els and de Bot 1987; Scovel 1995). Although it is possible to prove that certain segmental and prosodic features typical of a particular language are more indicative of a foreign accent, native speakers do not perceive these elements separately but holistically, i.e. together with other parameters such as fluency, hesitations, pauses, repetitions, false starts and rate of speaking (Magen 1998; McDermott 1986).

In spoken interaction between native and non-native speakers-but also between non-native speakers of various language backgrounds - some traces in L2 speech may indicate speech that is simply foreign-sounding, while others may severely impede communication. This distinction reveals the multi-dimensional nature of foreignaccented speech. From a methodological point of view, the fact that the degree of foreign accent is a difficult variable to measure gives additional credit to this assertion. Many scholars (Magen 1998; Munro \& Derwing 1999; Piske, MacKay \& Flege 2001) cast a critical eye on the research practice in the field and draw attention to the diversity of stimulus materials (authentic vs. synthetic speech, or a combination of both), the task types given (reading word-lists, sentences, short passages or free speech), the origin of the informants in respect of the typological distance between the two languages, as well as the phonetic expertise of the raters (untrained/naïve listeners vs. trained experts). The overall impression is that, although no approach emerges as all-encompassing, all approaches on their own yield satisfactory results. Findings by Munro and Derwing (1995, 1998, 1999), who examine the relationship between foreign-accentedness, intelligibility and comprehensibility, show that heavily accented speech is indeed more difficult for native speakers to perceive. However, even heavily accented speech is sometimes fully intelligible and comprehensible. In other words, the degree of foreign accent in itself does not hinder communication. In practice, factors which have the strongest impact on overall intelligibility and comprehensibility involve a combination of grammatical and pronunciation errors, with prosodic errors being perceived as potentially more damaging than phonetic errors. Another aspect that deserves attention is the relationship between accentedness and fluency. For instance, L2 learners tend to speak more slowly because their L2 morpho-syntactic knowledge is not fully developed and they require more time to process word meaning, while their articulation of segmental and prosodic elements is not sufficiently skilled (Munro \& Derwing 1998). With the improvement of their linguistic competence, together with greater L2 exposure and use, their speaking rate improves as well, thus reducing the traces of foreign accent in their speech (Derwing, Thomson \& Munro 2006).

\section{The current study}

The research findings surveyed above suggest a number of interesting ideas that will be investigated in this study. First, the interplay of the sound systems of two different languages, English and Macedonian, will be considered and the effect this has on the English pronunciation of Macedonian learners of English. We see the relevance of this aspect as the former language has been given huge attention in literature and research 
whereas the latter has been treated as a lesser investigated language. In addition, the phonologies of these two languages have only been described from a contrastive point of view in a study by Siljanoski (1976) but the conclusions have never been tested empirically. Second, with the globalisation and spread of the English language, it seems that native speakers tend to be more tolerant when it comes to the perception of foreign accents and are more critical of pronunciation errors that cause breach in communication than errors that deviate from the norm.

Hence, this study seeks to identify and describe the most frequent vocalic and consonantal markers of Macedonian-accented English speech as perceived by native speakers of English. By markers of foreign accent, we refer to the segmental sounds of the English phonological system which native speakers of English perceive as deviant (or mispronounced) from the standard variant of English they speak. Our research additionally sought to find out whether native speakers of different English variants perceive the same segments as non-native and, if so, to account for the general characteristics across the native groups.

\section{Methodology}

For the purposes of this study, we developed an experiment in which the English speech of Macedonian native speakers was evaluated by English native speakers with the use of a specially designed computer web application employed as a data gathering instrument.

\subsection{Participants}

Two types of speakers participated in the research undertaken for this study: (1) Macedonian learners of English recruited to provide speech samples of their English for evaluation; and (2) native speakers of English recruited to serve as 'raters' in the evaluation of the gathered speech samples. All participants completed a questionnaire and the information obtained was used to create the profiles of the two groups.

The 17 Macedonian speakers comprised a relatively homogenous group: all were students majoring in English Language and Literature at the University of Ss. Cyril \& Methodius; all were residents of Skopje aged between 19 and 25. Their level of English ranged from B2 $(n=6)$ to $\mathrm{C} 1(\mathrm{n}=11)$. None of the group had resided for any extended period in an English-speaking country. All reported a basic knowledge of other languages, including Spanish, Italian, German, French, Vlach, Czech, Russian, Serbian and Japanese.

One native speaker of (British) English was recruited to serve as the control speaker for the accent-rating section of the experiment, i.e. this speaker was recorded to provide a standard by which to assess the reliability of the other native-speaker evaluators. The choice of only one native control speaker was deliberate and aimed to eliminate native speaker variability in view of the small scale of this study and the consequent risk - as reported in Angelovska \& Hahn (2009) — of native speakers being rated as 'near-native', thus ranking them as non-native and thereby bringing into question the reliability of the native speakers acting as raters. 
A total of 14 native speakers of English completed the experiment and rated the speech samples obtained from the Macedonian learners. Their age ranged from 28 to 71 years old (median 49). All had university degrees or postgraduate qualifications $(\mathrm{PhD}=5$, $\mathrm{MA}=6, \mathrm{BA}=3$ ) and phonetic-phonological expertise. Some had prior experience as raters $(n=10)$. Most were either active or retired university lecturers $(n=8)$, while the remainder included English teachers $(n=4)$, a translator $(n=1)$ and a language consultant/book author $(n=1)$. As reported in the questionnaire, they spoke the following English variants: Southern British English ( $n=6)$, General American English $(n=6)$, Irish English $(\mathrm{n}=1)$ and Canadian English $(\mathrm{n}=1)$. All raters spoke additional languages with various degrees of proficiency, including German, Swedish, Irish, French, Spanish, Italian, Polish, Russian, Japanese, Chinese, Jewish and Arabic. Most of them had never interacted with speakers of Macedonian origin, though two raters reported brief exposure to Macedonian and Macedonian-accented English.

The raters were mostly recruited via the websites of LINGUISTLIST http://www.linguistlist.org/ and the IATEFL Pronunciation Special Interest Group PronSIG http://uk.groups.yahoo.com/group/iatefl_pronsig/. Additional methods employed for rater recruitment included direct approaches to experts in the field via email and personal acquaintance.

\subsection{Stimulus materials}

The Macedonian speakers and the control speaker were recorded in a soundproof booth using a Sound Forge 8.0 computer programme and a 20-channel 4-BuS Mixing Console Behringer MX2004A.

The speakers were each given a 'free speech' task in which they were asked to select one of four possible topics to speak about for 1-2 minutes. The recordings of their speech were then edited, i.e. long pauses were eliminated and levelled, and tested for authenticity. Out of 24 subjects initially recorded, the recordings of 7 subjects were subsequently eliminated as they did not pass the test of authenticity. The reasons for deselecting these recordings included: too many grammatical errors with occasional Macedonian interruptions; words and phrases that revealed the speaker's Macedonian origin; noticeable speech impediments with some sounds; and poor voice quality. The remaining 17 recordings, which passed the test, were used as speech stimuli for the native speakers to evaluate. Their average approximate duration was 17-29 seconds.

The topics included in the free speech task were intentionally designed to be general and personal so as to encourage the speakers to freely discuss matters that appealed to them in a relaxed manner (see Appendix for task instructions and a sample recording transcript). The rationale behind the adoption of this free-speaking task as the most appropriate to the purpose of the research included the following considerations (cf. Major 1986; Thompson 1991; Munro and Derwing 1994):

- To encourage a narrative style of spoken discourse resembling that of informal settings. (In preference, that is, to the reading of word-lists, sentences or paragraphs, which would generate speech resembling formal speech contexts and thus produce additional anxiety in the speakers. 
- To encourage speakers to focus more on the content of their speech than on the form of their delivery, hence the choice of topics with a personal and emotional overtone.

- To encourage a natural flow of speech by eliminating the possibility of speakers rehearsing set speeches.

- To avert the influence of English orthography on the speakers' pronunciation and any possible transfer of L1 reading skills-Macedonian being a language with phonetic orthography

- To avoid the risk of speakers misunderstanding or not knowing the meaning of words and therefore producing inarticulate speech — as might have happened if given set word-lists or texts.

\subsection{Web application: design, procedure, data collection and extraction}

The web application employed in this study is an example of an Internet-based research method developed as a user programme which aims to gather and store data as well as create an easily accessible database for further analysis. It consisted of several parts organized in separate webpages:

1) an introduction with instructions

2) a user account window

3) a participation agreement

4) a questionnaire for personal background details

5) experiment questions (Q1-Q4) with audio files (repeated for every speaker): (i) consonantal variables, (ii) vocalic variables, (iii) foreign accent ratings, and (iv) general variables for foreign accent evaluations

6) a comment box for users to insert their impressions of Macedonian-accented English

7) a comment box for remarks on the experiment format.

The raters were asked to listen to each individual speaker's audio file and answer the questions related to each file as instructed. Two types of data were collected: a) quantitative data on the frequency of phonetic segment variables and global foreign accent ratings on a 5-point scale (adapted from Bongaerts et al. 1997: 456); and b) qualitative data from open-ended questions with comment boxes. The variables used in experiment questions 1 and 2 (Figure 1) were selected on the basis of teaching experience and according to the most frequent mispronunciations reported in the literature consulted (Siljanoski 1976, 1993; Dimovska 1980; Weinberger 1998). The variables in Question 4 presented a selection of factors tested in other studies (Munro and Derwing 1998; McDermott 1986). 


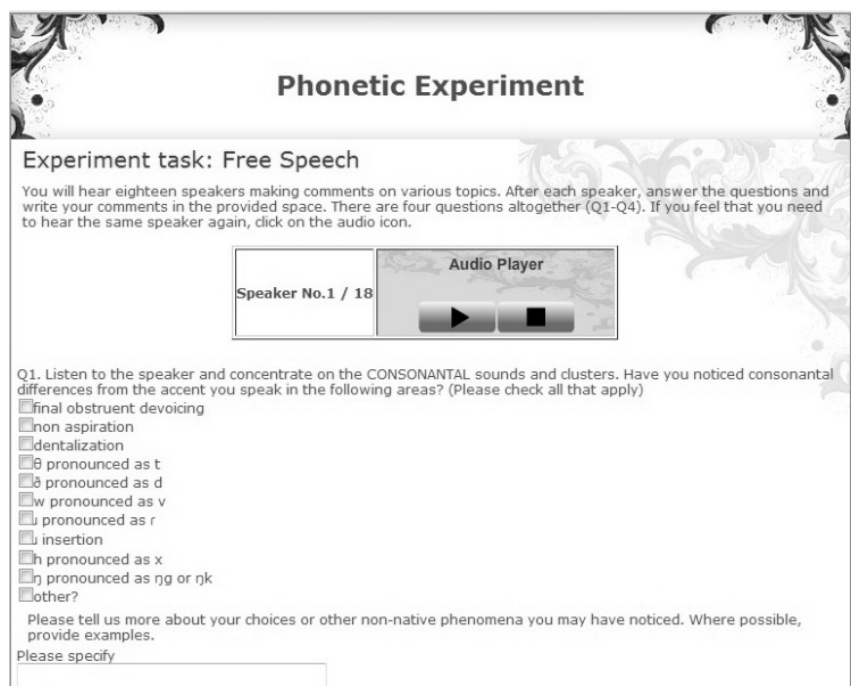

Fig. 1. Screenshot of the question web page (part)

The administrator first created accounts for each listener and then sent a username and password to each listener via e-mail. Having received the username and password, the listener was expected to log into the system at http://e-tech.feit.ukim.edu.mk/phonetics/. The user was then redirected to the next webpage to complete the experiment. If a listener did not complete the whole experiment in one sitting, they could log in again and continue where they had stopped, since the application kept track of the users' answers. The total duration of the experiment was approximately one hour (as reported by listeners who completed the pilot version of the experiment).

The development of this application enabled the creation of a small-scale corpus of listeners' responses. This allowed for access to pre-stored data that could subsequently be grouped for faster analysis. On completion of the experiment, the data was extracted in a readable format using Microsoft Word Excel 2007. The statistical analysis was conducted using the statistical package SPSS 16 in order to calculate the frequency of the checked responses only.

\section{Results}

The following analysis of results is divided into two parts. The primary analysis interprets the findings related to the frequency distribution of consonantal and vocalic segments in the English speech of Macedonian learners evaluated as non-native by English native speakers (ENS). Thus, the feedback from 12 native speakers - 6 British native speakers (BNS) and 6 American native speakers (ANS) - was considered as one group or as two separate groups. The additional analysis outlines several interesting phenomena that emerged from the answers given by all 14 native speakers, such as comparison of the results with the responses of the Canadian and Irish native speakers, and issues of intelligibility. 


\subsection{Primary analysis}

Inter-rater reliability was measured by comparing the values for global accent rating (GFA) given by the raters (Birdsong 2007; Derwing \& Munro 1997; Derwing, Thomson $\&$ Munro 2006). Foreign accent was treated as a one-dimensional phenomenon and the aim was to check whether all Macedonian native speakers (MN) would be evaluated as non-native speakers. Figure 2 presents the ratings given by the British and American raters for the free speech of the Macedonian participants. It can be seen that the endpoint values 1 ('no foreign accent') and 5 ('very heavy foreign accent') do not prevail among the participants, leading to the conclusion that foreign accent was detected in all participants - even in those with native-like pronunciation (MN8 and MN16). The dominant values for $\mathrm{MN1}$ to $\mathrm{MN6}$ are 3 and 4, indicating a more noticeable foreign accent. The dominant values for MN7 to MN17 are 2 and 3, indicating a less noticeable foreign accent. As can be seen on the figure, 3 is the most frequently marked value by the raters: thus, where several values are marked for a participant, they differ in one degree, namely 2 and 3 or 3 and 4, except for MN7 and MN15 where four different values are marked - and even then 3 prevails. In addition, the control speaker was given value 1 by all raters (the ratings for this speaker are not presented in Figure 2). From this high degree of consistency, one may conclude that the raters were able to notice aspects of non-native pronunciation in the spoken English of all the Macedonian participants.

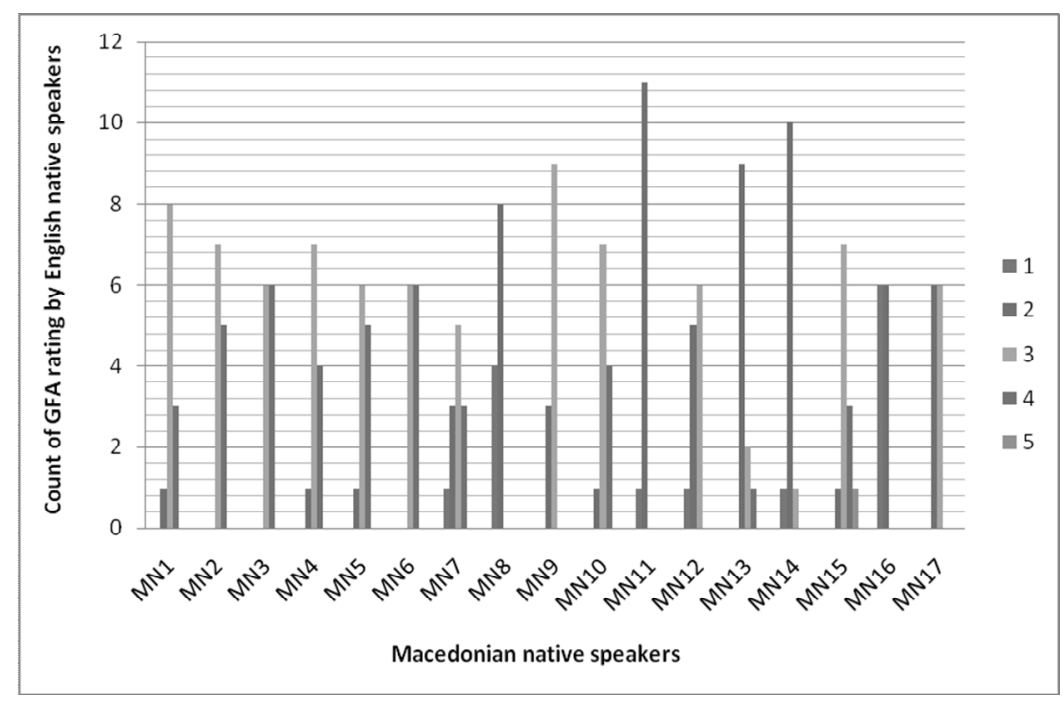

Fig. 2. Count of global foreign accent ratings by English native speakers ( $1=$ 'no foreign accent' to $5=$ 'very heavy foreign accent')

The frequency of the selected variables for the consonantal and the vocalic segments were calculated separately for the British and the American raters and then compared for each variable. The results for the consonantal variables are presented in Figure 3, where the number of checked responses for each variable is given on the horizontal axis (out of $\mathrm{N}=102$ calculated as the total number of possible responses). 


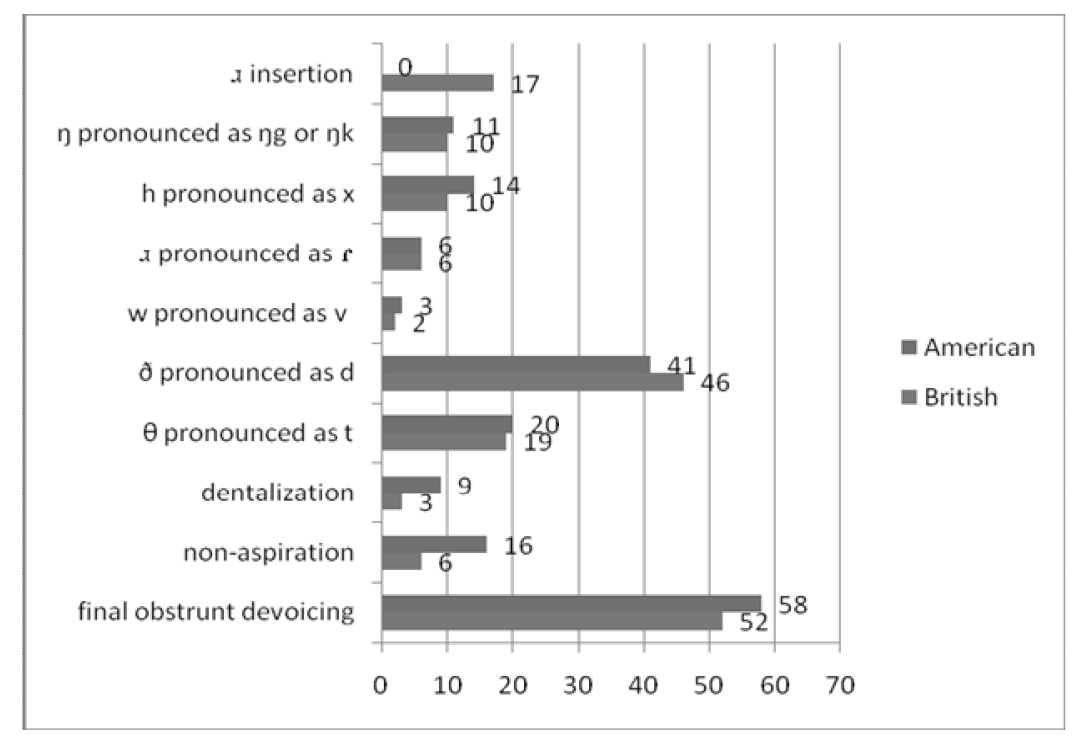

Fig. 3. Frequency distribution of consonantal variables

The highest frequency of perceived sound deviations is pointed out for final obstruent devoicing by both groups of raters (BNS 50.98\% and ANS 50.86\%). Another similarity is shown in the pronunciation of dental fricatives pronounced as dental plosives, i.e. $/ \mathrm{d} />/ \mathrm{d} / \mathrm{BNS} 45.10 \%$ and ANS 40.20\%), as well as $/ \theta />/ \mathrm{t} / \mathrm{BNS} 18.63 \%$ and ANS $19.61 \%$ ). Although some variables were less frequently checked by both groups of native speakers, some parallels do occur with: the English glottal fricative pronounced as Macedonian velar fricative, i.e. $/ \mathrm{h} />/ \mathrm{x} /$ (BNS $9.80 \%$ and ANS $13.73 \%$ ), velar plosives accompanying the pronunciation of the nasal velar, i.e. $/ \mathrm{y} />/ \mathrm{yK}, \mathrm{gg} /$ (BNS $9.80 \%$ and ANS $10.73 \%$ ), postalveolar / $/$ pronounced as an alveolar tap or trill (BNS=ANS 5,88\%), and bilabial approximants pronounced as labio-dental fricatives, i.e. $/ \mathrm{w} />/ \mathrm{v} /$ (BNS $1.96 \%$ and ANS 2.94\%).

As for the differences across the groups, it seems that the American raters were more sensitive to the non-aspiration of voiceless plosives /p, t, k/ (BNS 5.88 and ANS $15.69 \%$ ) and the dentalization of English alveolars /t, d/ (BNS 2.94\% and ANS 8.82\%). As anticipated, the British raters were more sensitive to the insertion of $/ \mathrm{A} /$ in preconsonantal and final word position (BNS 16.67\% and ANS 0\%).

Figures showing the frequency results for the vocalic variables indicate a higher degree of tolerance among native speakers for the pronunciation of vowels by Macedonian speakers. This is presented in Figure 4, where the number of checked responses for each variable is given on the horizontal axis (out of $\mathrm{N}=102$ calculated as the total number of possible responses). Both British and American raters predominantly perceived vowel shortening (BNS $46.08 \%$ and ANS $40.20 \%$ ). The other vocalic variables are rarely checked. It is evident that the differences between the groups are more indicative: unlike the British raters, the American raters are more sensitive to 


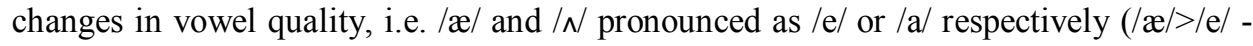
BNS 3.92\% and ANS 15.69\%; / $/>/ \mathrm{a} / \mathrm{-BNS} 5.88 \%$ and ANS $12.75 \%$ ).

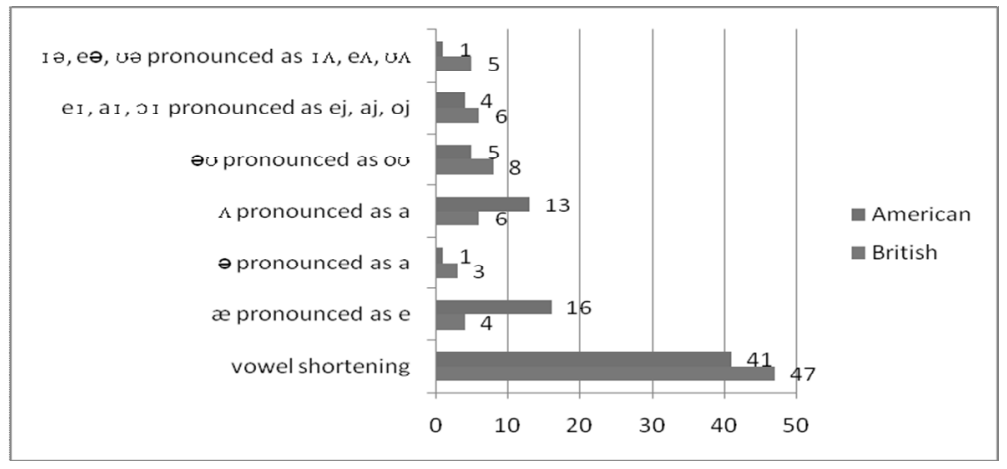

Fig. 4. Frequency distribution of vocalic variables

Although segmental analysis was the primary focus of the study, the fact that segmentals are only one aspect of speech and that speech is perceived in its entirety was not overlooked. Other parameters which influence the general impression of perceived speech and affect foreign-accentedness were included as variables in the experiment. For better comparison, native Macedonian speakers were subdivided into three groups according to the global accent ratings given by the raters:

- Group 1 (G1) consisted of participants with mean ratings from 1 to 2.5, indicating pronunciation perceived as good and native or near-native like.

- Group 2 (G2) consisted of participants with mean ratings from 2.5 to 3.5, indicating a noticeable foreign accent yet acceptable pronunciation.

- Group 3 (G3) consisted of participants with mean ratings from 3.5 to 5, indicating pronunciation perceived as poor and having a strong foreign accent.

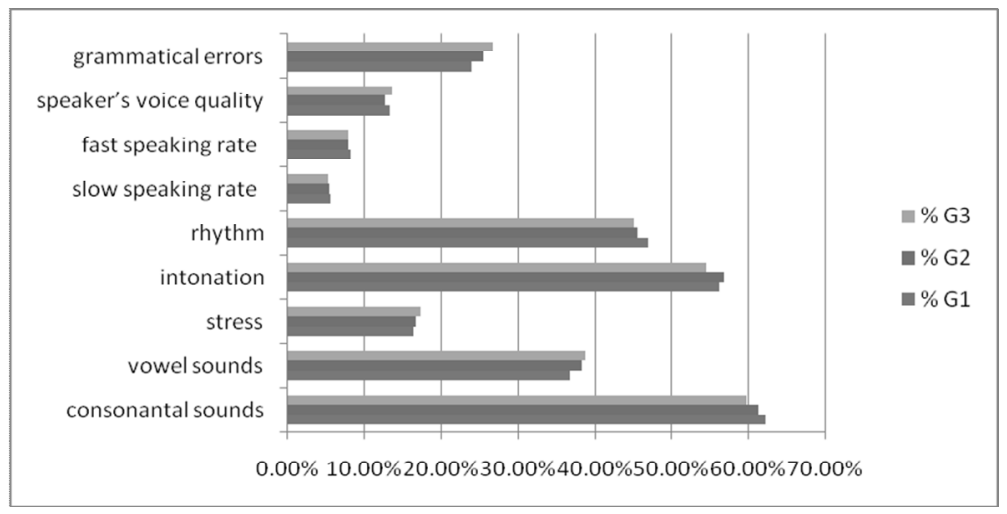

Fig. 5. Frequency distribution of general variables for foreign accent evaluation 
The results presented in Figure 5 are quite surprising. They show the order of the variables that influenced the general impression of foreign-accented speech, from most to least influential, as follows: (1) consonants; (2) intonation; (3) rhythm; (4) vowels; (5) grammatical errors; (6) stress; (7) speaker's voice quality; (8) fast speaking rate; (9) slow speaking rate.

More importantly, the graph illustrates the prevailing variables that indicate foreignaccentedness (even though one must point out that this dominance is pretty small yet it is indicative of an interesting occurance). Thus, when pronunciation is perceived as good and native or near-native like, it is the pronunciation of consonants that reveals nonnativeness in the speaker's speech; when the pronunciation is found acceptable, although the speaker speaks with a noticeable foreign accent, it is the intonation that is most striking as non-native; when the pronunciation is perceived as poor and as strongly foreign accented, the most striking features that influence native speaker perception are vowels and grammatical errors.

In the comment boxes, the raters were also asked to note any specific examples of words in which they noticed segmental deviations in pronunciation. In addition to words exemplifying some of the listed variables, the raters also pointed out deviations not included in the list. The results, including illustrative examples, can be summarized in three groups as follows:

a) segmental deviations

- final obstruent devoicing: days $(\mathbf{z}>\mathbf{s})$, and $(\mathbf{d}>\mathbf{t})$

- medial consonant voicing: increases $(\mathbf{s}>\mathbf{z})$

- fricative dentalization: thing $(\boldsymbol{\theta}>\mathbf{t})$, this $(\boldsymbol{d}>\mathbf{d})$

- fricative velarization: helping $(\mathbf{h}>\mathbf{x})$

- lateral velarization: life $([\mathbf{l}]>[\uparrow])$

- non aspiration: person $\left(\left[\mathbf{p}^{\mathbf{h}}\right]>[\mathbf{p}]\right)$, tennis $\left(\left[\mathbf{t}^{\mathbf{h}}\right]>[\mathbf{t}]\right)$

- consonant insertion: swimming $(\mathbf{y}+\mathbf{k} / \mathbf{g})$

- consonant deletion: $\operatorname{did} n^{\prime} t$ [dInt]

- vowel shortening: food (u:>u), talk (॰:>0), these (i:>i)

- vowel raising: sandy $(\mathbf{a}>\mathbf{e})$, children $(\mathrm{I}>\mathbf{i}), \operatorname{lot}(\mathrm{p}>\mathbf{0})$

- vowel lowering: love $(\Lambda>\mathbf{a})$, important $(\boldsymbol{\partial}>\mathbf{a})$, confidence $(\boldsymbol{\partial}>\mathbf{e})$

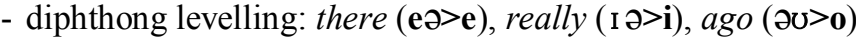

- overcorrection: consider ( $\mathrm{I}>\mathbf{i}:)$, ten $(\mathbf{t}>\boldsymbol{\theta})$, drama $(\mathbf{a}:>\mathfrak{x})$

- regional variant preference (Am. vs. Br.): sport (r-insertion), beautiful (t-voicing), class ( $\mathbf{a}:>\mathbf{x})$, abroad ( $(\mathrm{>}>\mathbf{a})$, stopped ( $\mathbf{p}>\mathbf{a})$

b) prosodic deviations

- rising intonation

- pauses in odd places

c) connected speech

- weak forms used scarcely or not used at all

- consonant deletion or insertion in final word position or at word boundaries 


\subsection{Additional analysis}

Given that single representatives cannot be treated as a group, the Canadian rater and the Irish rater were not included in the primary analysis. Nevertheless, their feedback demonstrated consistency with the overall results. Thus, they also perceived consonant deviations as most striking, particularly final obstruent devoicing. Except for the variable $/ æ /$ pronounced as /e/, which was marked by both raters, other vocalic adaptations were mainly accepted. The Irish rater also pointed out vowel shortening.

In the final part of the experiment, the raters were asked to give their general impressions of the Macedonian-accented English speech they had heard. Analysis of the comments submitted in this part reveals that, despite segmental substitutions and prosodic differences, Macedonian-accented English is regarded as: "easily/highly intelligible even when markedly non-native", "perfectly comprehensible", "not difficult to communicate with the speakers or to listen to them for lengthy periods" (as cited in the comments). It appears that non-English intonation and rhythm had a strong impact on their first impressions, as numerous comments were made regarding short tone units, staccato rhythm, lack of weak forms, unexpected pauses, unvarying sequences of rising tones, and repetitive intonation (in sum).

\section{Discussion}

The most obvious conclusion to be drawn from the results regarding consonants is that the most salient feature in the English speech of Macedonians as perceived by English native speakers is the devoicing of word final voiced consonants (obstruents). This finding corresponds to the predictions made by Siljanoski $(1976,1993)$ that such occurrence happens due to the direct transfer of an L1 phonological rule and has a limited distribution, while the fact that native speakers often point to it suggests negative transfer (Odlin 2000). On the other hand, instances where medial consonant voicing were noted can be accounted for as either a negative transfer of another typical Macedonian phonological rule, i.e. assimilation in voicing, or as an idiosyncratic overcorrection in the speech of individual participants.

It was anticipated that Macedonian speakers, in common with other L2 speakers, adapt the pronunciation of English consonants. The adaptations related to the place or manner of articulation demonstrate: a) a phonemic basis (when a sound does not exist in $\mathrm{L} 1$ and is thus pronounced as the closest L1 equivalent), and/or b) an allophonic basis (when a sound exists in L1 but is different from the L2 sound in one feature, thus is pronounced unconsciously as the L1 sound). An example of the former case is the pronunciation of English dental fricatives as Macedonian dental plosives $(/ \mathrm{d} />/ \mathrm{d} /$ and $/ \theta />/ t /$ ). Although these two sounds have low functional load (Catford 1987: 90), they are part of many frequently used grammatical words (Collins \& Mees 2006), which is probably why this variable was often observed in the speech samples. The reactions of the native speakers reflect Gimson's claims (Gimson 1994; Cruttenden 2001) that the English fricative system has to be fully acquired in order for minimum intelligibility to be achieved in communication. Another example is the pronunciation of bilabial $/ \mathrm{w} / \mathrm{as}$ labio-dental $/ \mathrm{v} /$, which is also judged as deviant by native speakers. It should be 
mentioned that there were only a few instances of this variable in the speech samples, which may account for the low frequency of checked answers; nevertheless, when it did appear, the native speakers regarded it as deviant. As for allophonic adaptations, these include the pronunciation of the English glottal fricative $/ \mathrm{h} /$ as the Macedonian velar fricative $/ \mathrm{x} /$, and English alveolar plosives as Macedonian dental plosives. Unlike $/ \mathrm{h} />/ \mathrm{x} /$, which was regarded as deviant by native speakers, the dentalization of English alveolar plosives was not treated as a relevant deviation due to the fact that it did not impede communication. A slightly different type of adaptation is the pronunciation of $/ \mathrm{g} /$, which is almost always accompanied by $/ \mathrm{k} /$ or $/ \mathrm{g} /$ in positions where these two sounds do not normally appear. The 'loss of phonemic status of $/ \mathrm{y} /$ ' is another instance of L1 transfer due to distributional similarities between the two languages (Giegerich 2005), since / $\mathrm{y} /$ in Macedonian exists only as an allophone of $/ \mathrm{n} /$ when followed by $/ \mathrm{k}, \mathrm{g} /$ (Siljanoski 1993).

Contrary to our expectations - and the observations of Cruttenden (2001) and Siljanoski (1993) - that voiceless plosive aspiration is a significant acoustic cue in English and affects the clarity of the conveyed message, the native-speaker raters in our study did not find it highly deviant. Another interesting finding that emerged from the raters' free comments was that the pronunciation of /1/ was perceived as 'rather hard'. This is surprising given that both palatalized and velarized allophones of $/ 1 /$ exist in English and in Macedonian and are acoustically similar. It appears that this phonetic aspect may have been poorly explained in the literature; upon additional examination of several examples in both languages, it became clear that there are indeed subtle allophonic distributional differences in prevocalic position-differences which were noticed as deviant by native speakers.

The insertion of $/ \mathrm{r} /$ in preconsonantal and final positions is a typical characteristic of Macedonian-accented English speech. The British raters perceived this as a deviation from the British accent, whereas the American raters did not find it obtrusive for it is in compliance with General American accent. In other words, the distributional differences in these English regional variants affect the pronunciation of Macedonian EFL learners, who use this option as a strategy for easier communication - a strategy commonly employed by other EFL learners of various language backgrounds according to Çelik (2008). However, adaptations in the place of articulation for this consonant are evident, as Macedonians neither pronounce it as the British postalveolar approximant nor as the American retroflex approximant but frequently opt for a tap or a trill.

When vowel articulations are analyzed, the findings conform to Flege's Speech Learning Model (Flege 1995, 2002, 2003), in particular the assumption that if temporal acoustic cues are not part of the L1 sound system then only the spectral acoustic cues of the L2 vowels are perceived by non-native learners, which is in accordance with the principle of phonetic similarity, and subsequently L2 vowels are "equated" to the closest L1 vocalic category. Having in mind that long vowels are non-existent in Macedonian, our findings concerning vowel shortening suggest that such "deflection", to use Flege's terminology, is promptly detected by native speakers. In addition, native speakers also perceive short vowel lengthening, the occurrence of which is probably due to: a) overcorrection; b) emphatic use of stress on the syllable containing the short vowel; or c) at word boundaries as pause filler or when the speaker hesitates. 
As Strange (2007) points out, L2 learners experience perceptual differentiation difficulty and are unable to appropriately articulate the L2 vowel due to cross-language phonetic similarity when sound systems differ in the size of their vowel inventories. Thus L2 vowels are interpreted as exemplars of the closest L1 vowel and are articulated in the identical manner as the L1 vowel is articulated. This being the case with English and Macedonian vowel inventories, our findings support the theoretical claims. It seems that the most difficult vocalic contrast for Macedonian learners of English is /e/-/æ/. These mispronunciations have a perceptual basis, as both members are so similar that they are perceived as belonging to the same category /e/. Similar tendencies are reported by other studies that have investigated vowel perception and production in learners of various language backgrounds (Bohn 1995; Flege \& MacKay 2004). One may conclude that the Macedonian five-member vowel inventory clearly influences the articulation of English vowels and that this is manifested as vowel raising and/or lowering when learners attempt to adapt their pronunciation. The same explanation seems reasonable for the pronunciation of $/ \mathrm{N} /$ as $/ \mathrm{a} /$ and $/ \mathrm{a} /$ as $/ \mathrm{N}$ or $/ \mathrm{a} /$ (subject to distributional position). The pronunciation of English diphthongs can be viewed as another instance of perceptual similarity accompanied with adaptations based on L1 influence. Although the descriptive statistical analysis of the results may point to the conclusion that diphthongs are not problematic sounds (because native speakers infrequently checked the variables), analysis of the raters' comments reveals quite the opposite. It seems that diphthongs, being non-existent sounds in Macedonian, are actually perceived and pronounced as monophthongs, with either the vocalic quality of the first element being adapted and slightly elongated or with clear articulation of both diphthongal elements.

Our examination of general variable data yielded the finding that consonants, intonation and vowels are the most influential indicators of the perceived degree of foreign accent. Regarding consonants and vowels, this finding supports the conclusion reached by many authors that proper consonant articulation is vital to spoken interaction in English and more important than non-native speaker's endeavours to authentically articulate English vowels (Cruttenden 2001; Jenkins 2000) - a fact that implies a need to reconsider priorities in the teaching of pronunciation.

The influence of L1 intonation, on the other hand, has been reported in many studies as the strongest predictor of foreign accent (van Els \& de Bot 1987; Anderson-Hsieh, Johnson \& Koehler 1992; Magen 1998; Moyer 1999). Given the free-speaking tasks assigned as speech stimuli in our experiment, this result was anticipated. Although prosodic features were not the aim of this study, they were spontaneously perceived by the raters as deviating from the native speakers' model and as reflecting the following prosodic features of Macedonian: short tone units, frequent pausing, rising tones, and equal frequency/length of stressed and unstressed syllables resulting in failure to use reduced forms and distorted rhythm.

In addition to phonology, other linguistic levels must be taken into consideration when evaluating non-native accent, including, syntax, morphology, lexical fluency and idiomatic use. During the language acquisition process, these domains are not constant but are subject to changes, improvement or fossilization (Ellis 1995) - as is evident in the grammatical errors made by L2 speakers. Because speech is holistically evaluated, native speakers also tend to perceive these elements as non-native (Derwing \& Munro 1997; Moyer 1999). This cumulative effect emerged in our study as well, with some 
raters submitting comments about repeated grammatical errors and the use of nonidiomatic phrases.

A finding worthy of note is the general impression reported by the native speakers in our study that Macedonian-accented English is highly intelligible. Such comments were given even to subjects who were rated as having a heavy foreign accent. This corroborates the findings of Munro and Derwing's research into the multidimensional nature of foreign accent. In their studies, they conclude that, "although some features of accent may be highly salient, they do not necessarily interfere with intelligibility" (Derwing \& Munro 1997: 11); and, furthermore, "the presence of a strong foreign accent does not necessarily result in reduced intelligibility and comprehensibility" (Munro \& Derwing 1999: 303). However, it should be pointed out that individual evaluations of intelligibility and comprehensibility were not carried out in our study. It could be argued that this is a drawback of the study, as evaluations are very subjective. Although partial control was imposed by requiring the raters to make a forced choice (the program would return them to the unanswered section otherwise), we cannot know how quickly they answered the questions or whether they changed their first impressions before submitting their responses.

As a final point, from a methodological point of view, some limitations related to the choice of a free speech task as a speech stimulus were discovered. Although the subjects produced authentic speech featuring typical mispronunciations (which was very constructive for the outcomes), the recordings revealed that not all expected phonetic/phonological structures naturally emerged, i.e. there was no guarantee that every segmental variable on the list would be mentioned by all subjects at least once in their speech samples, which directly influenced the frequency of the raters' responses. A modified free speech task should perhaps be considered in future research. Such a task might involve a choice of several topics and a set of phrases with segments under investigation for the subject to include in his/her speech. However, to preserve speech spontaneity, care should be taken not to overburden the phrases with too many difficult elements or allow subjects excessive preparation time.

\section{Conclusion}

Based on the data analysis and discussion in this research study, it may be concluded that the three most indicative segmental markers of foreign accent in the English speech of Macedonian EFL learners are as follows: final obstruent devoicing, vowel shortening (or non-discrimination of vowel length), and substitution of English (inter)dental fricatives with dental plosives.

The close connection between the first and the second marker is worthy of remark given the English rule of pre-fortis clipping. It appears that whenever Macedonian learners devoice a consonant in final word position, the preceding vowel is automatically shortened. This eliminates significant information in the acoustic signal for native listeners who might therefore not understand the message and need to resort to relying more on the context than the phonological meaning or to requesting further clarification from the speaker. 
Another conclusion that can be drawn from the results is that not all norm-deviating pronunciations are equally weighted by native speakers. Those that are potential sources of unintelligibility and thus may cause a breakdown in communication are regarded as most deviant. Segmental substitutions are generally accepted with relative tolerance. In addition, it appears that native speakers gradually adapt and develop flexibility towards the foreign-accented speech to which they are exposed. While this thread has already received some attention in the field of accent studies yielding positive results with accent-trained native speakers (Derwing, Rossiter and Munro 2002), further evidence is needed regarding the psychological factors that interact in native speakers such as their attitudes towards L2 accented speech.

When considering the Macedonian context of learning English, the findings of this study are likely to prove quite useful if implemented in teaching practice. Most authors agree (Derwing \& Rossiter 2003; Moyer 1999; Derwing, Munro \& Wiebe 1998) that if a learner's goal is to acquire native-like pronunciation, the type of pronunciation instruction should relate to learner's language proficiency level: the lower the level, the higher the benefit of segmental instruction, while advanced learners would benefit most from prosodic instruction in the improvement of their discourse fluency. At an academic level, phonetic training should incorporate exercises for: sound perception (focus on target contrasts through high exposure to authentic spoken materials), sound production (focus on target sounds and suprasegmentals), and raising of phonetic awareness. However, if the learner's goal is to use English for international communication with both native and non-native speakers, intelligibility is prioritized over the level of proficiency. The suggestions made by Jenkins in the Lingua Franca Core (Jenkins 2000: 159) might be adapted on the basis of the learner's language background (e.g. Macedonian) and used as helpful pointers in teaching, especially when little time is assigned to pronunciation instruction.

The findings presented in this paper are far from exhaustive and definitive; on the contrary, we feel that they are much more indicative than significant and would provide a good basis for future research in this area. As with similar studies, additional questions have arisen that need further scientific support-such as the influence of sound perception on difficult sounds, the acquisition of nuclear stress placement and the English intonation model, and factors that influence foreign-accentedness in Macedonian EFL learners.

\section{Acknowledgements}

I am extremely grateful to all participants in this study. This research could not have been completed without the generous contributions of $\mathrm{Dr}$ Teresa O'Brien from the University of Manchester, Dr Marija Janeva-Mihajlovska and Matthew Jones from the University of Skopje, and Tanja Angelovska from the University of Munich. Their guidance, helpful advice and useful comments throughout the course of conducting this research are much appreciated. I would also like to thank Dr Dimitar Trajanov, Vlatko Apostolski and Goran Bakraceski from the Faculty of Electrical Engineering and Information Technologies, Skopje University, for their support with the design of the web application. 


\section{References}

Anderson-Hsieh, J. and K. Koehler. 1988. The effect of foreign accent and speaking rate on native speaker comprehension. Language Learning 38 (4), 561-613.

Anderson-Hsieh, J., R. Jonson and K. Koehler. 1992. The relationship between native speaker judgements of non-native pronunciation and deviance in segmental, prosody and syllable structure. Language Learning 42 (4), 529-555.

Angelovska, T. and A. Hahn. 2009. English with a "native-like" accent: An empirical study on native speakers' perceptions. In Benati, A. (ed.), Issues in Second Language Proficiency. London: Continuum Publishing. 147-166.

Archibald, J. 1998. Second Language Phonology. Amsterdam: John Benjamins Publishing.

Best, C. T. 1995. A direct realist view of cross-language speech perception. In Strange, W. (ed.), Speech Perception and Linguistic Experience: Theoretical and Methodological Issues in Cross-Language Speech Research. Timonium, MD: York Press. 171-203.

Birdsong, D. 2007. Native-like pronunciation among late learners of French as a second language. In Bohn, O.-S., and M. J. Munro. (eds.), Language Experience and Second Language Speech Learning: In honour of James Emil Flege (pp. 99-117). Amsterdam: John Benjamins.

Bohn, O.-S. 1995. Cross-language speech perception in adults: First language transfer doesn't tell it all. In Strange, W. (ed.), Speech Perception and Linguistic Experience: Theoretical and Methodological Issues in Cross-Language Speech Research. Timonium, MD: York Press. 279-304.

Bongaerts, T., C. van Summeren, B. Planken and E. Schils. 1997. Age and ultimate attainment in the pronunciation of a foreign language. Studies in Second Language Acquisition 19, 447-465.

Brennan, E. M. and J. S. Brennan. 1981. Accent scaling and language attitudes: Reactions to Mexican American English speech. Language and Speech 23 (3), 207221.

Brown, C. 1998. The role of L1 grammar in the L2 acquisition of segmental structure. Second Language Research 14 (2), 36-193.

Catford, J. C. 1987. Phonetics and the teaching of pronunciation: A systemic description of English phonology. In Morley, J. (ed.), Current Perspectives on Pronunciation. Washington, DC: TESOL. 87-99.

Çelik, M. 2008. A description of Turkish-English phonology for teaching English in Turkey. Journal of Theory and Practice in Education 4 (1), 159-175.

Collins, B. and I. M. Mees. 2006. Practical Phonetics and Phonology: A Resource Book for Students. London: Routledge.

Cruttenden, A. (ed.). 2001. Gimson's Pronunciation of English. 6th edition. London: Arnold.

Derwing, T. M. and M. J. Munro. 1997. Accent, comprehensibility and intelligibility: Evidence from four L1s. Studies in Second Language Acquisition 19, 1-16.

Derwing, T. M., M. J. Munro and G. Wiebe. 1998. Evidence in favour of a broad framework for pronunciation instruction. Language Learning 48 (3), 393-410. 
Derwing, T. M. and M. J. Rossiter. 2003. The effects of pronunciation instruction on the accuracy, fluency and complexity of L2 accented speech. Applied Language Learning 13 (1), 1-17.

Derwing, T. M., M. J. Rossiter and M. J. Munro. 2002. Teaching native speakers to listen to foreign-accented speech. Journal of Multulingual and Multicultural Development 23 (4), 245-259.

Derwing, T. M., R. I. Thomson and M. J. Munro. 2006. English pronunciation and fluency development in Mandarin and Slavic speakers, System 34 (2), 183-193.

Dimovska, P. 1980. An Outline of the Pronunciation of English. Skopje: Ss. Cyril and Methodius University.

Ellis, R. 1995. Understanding Second Language Acquisition. Oxford: OUP.

Escudero, P. 2005. Linguistic Perception and Second Language Acquisition. PhD Thesis. Utrecht: LOT.

Flege, J. E. 1984. The detection of French accent by American listeners. Journal of the Acoustical Society of America 76 (3), 692-707.

Flege, J. E. 1995. Second language speech learning: Theory, findings and problems. In Strange, W. (ed.), Speech Perception and Linguistic Experience: Theoretical and Methodological Issues in Cross-Language Speech Research. Timonium, MD: York Press. 233-277.

Flege, J. E. 2002. Interactions between the native and second-language phonetic systems. In Burmeister, P., T. Piske and A. Rhode (eds.), An Integrated View of Language Development: Papers in honor of Henning Wode. Trier: Wissenschaftlicher Verlag. 217-244.

Flege, J. E. 2003. Assessing constraints on second-language segmental production and perception. In Meyer, A. and N. Schiller (eds.), Phonetics and Phonology in Language Comprehension and Production, Differences and Similarities. Berlin: Mouton de Gruyter. 319-355.

Flege, J. E. and I. R. A. MacKay. 2004. Perceiving vowels in a second language. Studies in Second Language Acquisition 26, 1-34.

Giegerich, H. J. 2005. English Phonology. Cambridge: CUP.

Gimson, A. C. 1994. An Introduction to the Pronunciation of English, revised $4^{\text {th }}$ edition. London: Edward Arnold.

Hansen, J. 2006. Acquiring a Non-Native Phonology: Linguistic Constraints and Social Barriers. London: Continuum IPG Ltd.

Jenkins, J. 2000. The Phonology of English as an International Language. Oxford: OUP.

Kirkova-Naskova, A. 2009. Markers of Foreign Accent in Macedonian-English Interlanguage. Unpublished MA Thesis. Skopje: Faculty of Philology.

Kuhl, P. 2000. A new view of language acquisition. Proceedings of the National Academy of Sciences USA, 97, 11850-11857.

Leather, J. and A. James. 1996. Second language speech. In Ritchie, W.C. and T. K. Bahtia (eds.), The Handbook of Second Language Acquisition. San Diego: Academic Press, Inc. 269-316.

Magen, H. 1998. The perception of foreign-accented speech. Journal of Phonetics 26 (4), 381-400.

Major, R. C. 1986. Paragoge and degree of foreign accent in Brazilian English. Second Language Research 2, 53-71. 
Major, R. C. 1998. Interlanguage phonetics and phonology: An introduction. Studies in Second Language Acquisition 20, 131-137.

Major, R. C. 2001. Foreign Accent: The Ontogeny and Phylogeny of Second Language Phonology. Mahwah, New Jersey, London: Lawrence Erlbaum Associates Publishers.

McDermott, W. L. C. 1986. The Scalability of Degrees of Foreign Accent. PhD Thesis. Ithaca, NY: Cornell University.

Moyer, A. 1999. Ultimate attainment in L2 phonology: the critical factors of age, motivation, and instruction. Studies in Second Language Acquisition 21, 81-108.

Munro, M. J. and T. M. Derwing. 1995. Processing time, accent, and comprehensibility in the perception of native and foreign-accented speech. Language and Speech 38 (3), 289-306.

Munro, M. J. and T. M. Derwing. 1998. The effects of speaking rate on listener evaluations of native and foreign-accented speech. Language Learning 48 (2), 159182.

Munro, M. J. and T. M. Derwing. 1999. Foreign accent, comprehensibility and intelligibility in the speech of second language learners. In Leather, J. (ed.), Phonological Issues in Language Learning. Oxford: Basil Blackwell. 285-310.

Odlin, T. 2000. Language Transfer: Cross-Linguistic Influence in Language Learning. Cambridge: CUP.

Pennington, M. C. 2007. The context of phonology. In Pennington, M. C. (ed.), Phonology in Context. Basingstoke: Palgrave. 1-24.

Piper, T. and D. Cansin. 1988. Factors influencing the foreign accent. The Canadian Modern Language Review 44 (2), 334-342.

Purcell, E. T. and R. W. Suter. 1980. Predictors of pronunciation accuracy: A reexamination. Language Learning 30 (2), 271-287.

Piske, T., I. MacKay and J. E. Flege. 2001. Factors affecting degree of foreign accent in an L2: A review. Journal of Phonetics 29, 191-215.

Scovel, T. 1995. Differentiation, recognition and identification in the discrimination of foreign accents. In Archibald, J. (ed.), Phonological Acquisition and Phonological Theory. Hillsdale, NJ: Lawrence Erlbaum. 161-181.

Siljanoski, V. 1976. A Contrastive Analysis of English and Macedonian Phonological Systems. PhD Thesis. Skopje: Faculty of Philology.

Siljanoski, V. 1993. Introduction to English Pronunciation. Skopje: Ss Cyril and Methodius University.

Strange, W. 2007. Cross-language phonetic similarity of vowels: theoretical and methodological issues. In Bohn, O.-S. and M. J. Munro (eds.), Language Experience and Second Language Speech Learning: In honour of James Emil Flege. Amsterdam: John Benjamins. 35-56.

Thompson, I. 1991. Foreign accents revisited: The English pronunciation of Russian immigrants. Language Learning 41 (2), 177-204.

van Els, T. and K. de Bot. 1987. The role of intonation in foreign accent. The Modern Language Journal 71 (2), 147-155.

Weinberger, S. H. 1998. The speech accent archive [electronic database]. George Mason University. http://accent.gmu.edu/index.php 


\section{Appendix}

\section{Task instructions: Free speech}

You are about to talk on a chosen topic and be recorded while talking. Please silently look at the topics below. Choose ONE that you would like to briefly comment on in English. Your response need be only 7-10 sentences (approximately 1-2 minutes of speech).

Please try not to reveal any personal information such as your mother tongue, nationality, place of birth, place of residence, age, etc. Try to speak at your normal speaking rate. Say your name before you begin.

A. Describe an experience you had which was meaningful in your life: Who was involved? How old were you? How did this influence you?

B. Describe an issue or subject matter you are vitally interested in: Why is this important for your life? How did you become so interested in it? What has shaped your views and knowledge of the subject?

C. Describe a person in your life who means a lot to you: How do you know this person? Why is he/she significant in your life?

D. A topic of your own choice.

\section{Sample recording transcript of MNS1:}

I was taking drama classes and this experience was really meaningful for me and important. We were a group of about ten people and our teachers were actors. I think that the things I learned there will make my life easier in a lot of ways. 